\title{
The impact of the North American waterbug Trichocorixa verticalis (Fieber) on aquatic macroinvertebrate communities in southern Europe
}

\author{
Frank Van de Meutter ${ }^{1, *}$, Hendrik Trekels ${ }^{1}$ and Andy J. Green ${ }^{2}$ \\ With 3 figures and 1 table
}

\begin{abstract}
The North American waterbug Trichocorixa verticalis (Heteroptera: Corixidae) has recently invaded brackish water systems on three continents. Despite its potential to be a keystone species in hypersaline waters in its home range, its effect on the communities it invades is yet unstudied. By doing a field survey in 29 ponds in Doñana, southern Europe some years after T. verticalis was first recorded there, we aimed to establish its prevalence and impact on the local invertebrate community, especially the local corixid community with which it is likely to compete. T. verticalis showed the highest prevalence among all seven Corixidae species found. It occasionally reached high local abundance, especially at high salinity. T. verticalis also appeared to be better than native Corixidae at coping with human disturbance. We could not identify significant effects of $T$. verticalis on the local corixid community nor on the invertebrate community at large. Further experimental research will be needed to confirm these results. Special attention should be paid to hypersaline systems where T. verticalis may act as a top predator.
\end{abstract}

Key words: exotic, ecological impact, Corixidae, non-native insect, anthropogenic disturbance.

\section{Introduction}

The increasing establishment of invasive species outside their native range is one of the most important threats to global biodiversity (IUCN 2008). Not all invasions have a large ecological impact, and relatively few invasive species are responsible for most of the current threats to biodiversity. Dramatic effects of invader species on host communities are mainly found in the case of ecosystem engineers where alterations of key aspects of the habitat may have ramifications throughout the community (Crooks 2002), as a result of strong trophic interactions such as herbivory (Joe \& Daehler 2008), predation (Salo et al. 2007) and parasitism (Maloney et al. 2005) or through competition
(Reitz \& Trumble 2002). Increasing attention is now given to predicting the ecological impact of newly invading species (e.g. from life-history traits), since this helps prioritization of efforts to safeguard biodiversity. However, predicting ecological impact remains difficult, particularly with respect to trophic interactions where novel and sometimes unexpected interactions may emerge (Caroll \& Fox 2007, Mondor \& Addicott 2007). Experimental and field evaluations therefore remain vital.

Global diversity scenarios (Sala et al. 2000) predict that bio-invasions will rank fourth among the most important drivers of biodiversity loss in 2100 , and will be the dominant cause of decline in particular regions, such as the Mediterranean biome. If we use the Iberian

\footnotetext{
Authors' addresses:

${ }^{1}$ Laboratory of Aquatic Ecology and Evolutionary Biology, Katholieke Universiteit Leuven, Ch. Debériotstraat 32, 3000 Leuven, Belgium.

${ }^{2}$ Wetland Ecology Department, Estación Biológica de Doñana, CSIC, C/ Américo Vespucio s/n, E-41092 Sevilla, Spain.

*Corresponding author; email: Frank.VandeMeutter@bio.kuleuven.be
} 